ISSN 2525-4812 (versão online) ISSN 2238-7641 (versão impressa) http://www.revistaterceiramargem.com/ index.php/terceiramargem/index
Recebido em: 19/6/2019

Aprovado em: 30/2/2020

Período de publicação: jul/dez, 2020
Revista Terceira Margem Amazônia

(v. $6 \cdot$ n. $15 \cdot J u l / \operatorname{Dez} 2020)$

Como citar o artigo:

SANTOS, D. I. P dos. COSTA, F. S. Adaptabilidade ribeirinha diante das variações de seca e cheia do Lago Jenipapo (Manicoré/AM). Revista Terceira Margem Amazônia, v. 6, n.15, p. 103-113, 2020. Doi: http://dx.doi.org/10.36882/25254812.2020v6i15p103-113.

\title{
ADAPTABILIDADE RIBEIRINHA DIANTE DAS VARIAÇÕES DE SECA E CHEIA DO LAGO JENIPAPO (MANICORÉ/AM)
}

\author{
Danielle Ivana Pereira dos Santos ${ }^{1}$ \\ Francimara Souza da Costa ${ }^{2}$
}

\begin{abstract}
Resumo: A incidência de secas e cheias severas dos rios tem sido intensificada nos últimos anos na Amazônia, tornando o conhecimento das estratégias adaptativas dos ribeirinhos essencial para o desenvolvimento de políticas públicas e planos de prevenção e mitigação mediante à ocorrência desses eventos. Esse estudo identificou as estratégias e ações de adaptabilidade construídas pelas famílias moradoras das comunidades Bracinho e Braço Grande, diante das variações de seca e cheia do Lago do Jenipapo. As comunidades estão situadas no Projeto de Assentamento Agroextrativista (PAE) Jenipapo, no município de Manicoré, Estado do Amazonas, e possuem relação direta com o Lago Jenipapo, cuja água é utilizada para tráfego, consumo doméstico, atividades de lazer, dentre outros usos. Foram realizadas entrevistas com os moradores, observando-se que as variações sazonais determinam o modo de vida no local, exercendo influência direta sobre as formas de construção das moradias, mudanças nos hábitos alimentares e adaptações das atividades econômicas.
\end{abstract}

Palavras-chaves: assentamento, Amazônia, eventos extremos

Abstract: The incidence of droughts and severe river floods has been intensified in recent years in the Amazon, making knowledge of the adaptive strategies of riverine residents essential for the development of public policies and plans for prevention and mitigation through the occurrence of these events. This study identified the adaptability strategies and actions built by the families living in the Bracinho and Braço Grande communities, in the face of drought and flood variations in Lago do Jenipapo. The communities are located in the Jenipapo Agroextractive Settlement Project (PAE), in the municipality of Manicoré, State of Amazonas, and have a direct relationship with Lake Jenipapo, whose water is used for traffic, domestic consumption, leisure activities, among other uses. Interviews were conducted with residents, observing that seasonal variations determine

\footnotetext{
${ }^{1}$ Mestre em Ciências Ambientais, Universidade Federal do Amazonas, danielle_ivana@hotmail.com ${ }^{2}$ Doutora em Ciências Socioambientais, Professora da Universidade Federal do Amazonas, francimaracosta@yahoo.com.br
} 
Adaptabilidade ribeirinha diante das variações de seca e cheia do Lago Jenipapo (Manicoré/AM)

the way of life in the place, exercising a direct influence on the forms of housing construction, changes in eating habits and adaptations of economic activities.

Keywords: settlement, Amazon, extreme events

\section{INTRODUÇÃO}

A Amazônia é composta por basicamente dois grandes grupos de ecossistemas: áreas inundáveis compostas pelas terras de várzeas, como os igapós e os furos, e as áreas de florestas de terra firme, como as florestas altas e densas, as florestas baixas, as savanas, os cerrados e os campos naturais (SCHERER, 2004).

Diferente das populações que habitam as áreas de terra firme, os ribeirinhos caracterizam-se por viverem às margens de corpos hídricos, tais como igarapés, igapós e lagos que compõem o vasto e complexo estuário amazônico. O cotidiano dos "Povos das Águas" está condicionado ao ciclo da natureza, pois o fenômeno da enchente e da vazante regula em grande parte o seu dia-a-dia, de tal modo que o mundo do trabalho e das relações obedece ao ciclo sazonal (SCHERER, 2004).

Os ribeirinhos estabelecem uma relação harmônica com o rio, pois além de ser o lugar de moradia, é também o espaço de produção, de onde é retirado o sustento de sua família. Contrariamente à visão preconceituosa da lógica capitalista que concebe os ribeirinhos como "atrasados", esse grupo possui modo de vida próprio, com seu próprio período de trabalho, aproveitando e respeitando os recursos e os ciclos naturais que o cercam.

Diante da sazonalidade marcada pelas cheias cíclicas dos rios, os ribeirinhos necessitam se adaptar para o enfrentamento das adversidades, que variam de acordo com constituição social e ambiental do local. Assim como a subida e descida dos rios regulam o ciclo de vida da biota local, a dinâmica dos rios comanda todas as atividades desenvolvidas pelas populações humanas que residem nesses ambientes (PEREIRA, 2007).

Este estudo caracteriza os processos de adaptabilidade das comunidades que habitam o Lago Jenipapo, localizado no município de Manicoré, Estado do Amazonas. O conhecimento desses processos possibilita o desenvolvimento de estratégias para melhoria das condições de vida nessas áreas, conciliando a conservação dos diferentes modos de vida e dos recursos naturais da área (MARENGO \& ESPINOZA, 2016). 
Adaptabilidade ribeirinha diante das variações de seca e cheia do Lago Jenipapo (Manicoré/AM)

A pesquisa parte da premissa que os ribeirinhos amazônicos estão em constante processo de adaptação. Caracterizar essas estratégias e socializá-las poderá fornecer informações aos formadores de políticas, bem como à sociedade, diante da constante intensificação de eventos climáticos extremos.

Os resultados poderão ainda colaborar e nortear as autoridades municipais para o fortalecimento das capacidades resilientes dos ribeirinhos, no que tange à flexibilidade para sobrevivência, à aprendizagem e à adaptação durante episódios imprevisíveis de mudanças no regime hidrológico do Rio Madeira no Estado do Amazonas.

\section{METODOLOGIA}

A área estudada caracteriza-se como um Projeto de Assentamento Agroextrativista (PAE), localizado no Lago Jenipapo (Manicoré/AM). O PAE foi criado em 2004 e possui uma área total de 48.547 ha, com capacidade prevista para 450 famílias. A área é gerida pelo Instituto Nacional de Colonização e Reforma Agrária (INCRA) e atualmente conta com 404 famílias assentadas em 14 comunidades (INCRA, 2018).

As comunidades locais têm relação direta no uso da água com o Lago Jenipapo, principalmente no que diz respeito à navegabilidade, pois esse corpo hídrico constitui-se na principal rota até o Rio Madeira e à cidade de Manicoré. Também é utilizado para tráfego das crianças para as escolas, uso doméstico e para o escoamento da produção.

Para a coleta de dados foram selecionadas as comunidades Bracinho e Braço Grande, devido a maior facilidade de acesso às residências. As informações foram coletadas por meio de entrevistas semiestruturadas junto aos moradores das comunidades. Foi utilizada amostragem não-probabilística intencional, na qual foram pré-definidos os entrevistados que possuíam idade igual ou superior a 18 anos, reconhecidos (as) como o (a) chefe da família.

Para a seleção dos entrevistados foi utilizada a técnica "bola de neve" ("Snow ball") (WHA, 1994), onde a partir do contato inicial com a comunidade, um primeiro informante, preferencialmente a pessoa reconhecida como líder, indica outros moradores, e assim sucessivamente até atingir o ponto de saturação.

Foram entrevistadas $30 \%$ das famílias residentes em cada comunidade a fim de obter informações sobre suas estratégias de adaptação durante os episódios de seca e cheia do lago Jenipapo. Os dados foram tabulados em planilhas eletrônicas e submetidos à 
Adaptabilidade ribeirinha diante das variações de seca e cheia do Lago Jenipapo (Manicoré/AM)

análise a partir da estatística descritiva, com o cálculo da média expressa na descrição dos resultados e na forma de quadro.

\section{ADAPTABILIDADE RIBEIRINHA DIANTE DAS VARIAÇÕES DE SECA E CHEIA}

A água é um dos símbolos reconhecidamente mais importantes do ambiente no hábitat. De acordo com Sternberg (2016, p. 14), “a água constitui o elemento da paisagem através do qual mais agudamente se sentem as vinculações do homem com o meio". Nesse sentido, entende-se a relevância do estudo da adaptabilidade humana em relação ao movimento das águas para compreender suas modificações ao longo das ocupações e vivências em áreas alagadiças (várzeas).

Os ecossistemas de várzeas se caracterizam por um processo de complexa transformação e instabilidade (FERRARA, 1999) e por isso sua ocupação necessita do desenvolvimento de habilidades que permitam às pessoas o aproveitamento dos recursos e a superação das dificuldades para a permanência no local.

Para Moran (2010), essas habilidades estão relacionadas às capacidades humanas para adaptação ao ambiente em que vive, capacidades relacionadas a características funcionais e estruturais que auxiliam no enfrentamento das alterações ambientais e condições de estresse. Segundo o autor:

\footnotetext{
"Os seres humanos encontram-se envolvidos em um processo constante de interação dinâmica com o meio que os cerca. Como espécie, enfrentamos problemas com diversos graus de complexidade. Um tipo de estresse prevalecerá, às vezes, enquanto, outras vezes, temos de nos ajustar a diversos obstáculos de natureza bastante distinta. As respostas a esses obstáculos nem sempre representam as 'melhores' opções, mas expressam ajustes entre as várias pressões exercidas sobre o organismo" (Moran, 2010, p. 384-385).
}

Entretanto, a adaptação abordada nesse estudo não se trata dos processos biológicos e orgânicos apontados por Moran, apesar de ocorrerem em alguma medida no ambiente amazônico, devido à necessidade de permanência em muitas horas sob sol forte, ou da força necessária nas atividades produtivas, mas refere-se às estratégias cognitivas e de comportamento que permeiam a vida dos ribeirinhos amazônicos e que lhes dão as possibilidades para permanecerem comportando riscos e incertezas.

Olson (1999) sugerem que avaliar a adaptabilidade humana seja a melhor tentativa para compreender a dinâmica do funcionamento de um sistema, auxiliando assim as 
Adaptabilidade ribeirinha diante das variações de seca e cheia do Lago Jenipapo (Manicoré/AM)

tomadas de decisões em uma governança adaptativa e incrementando a melhoria da gestão dos recursos naturais diante de eventos climáticos extremos e imprevisíveis.

\section{RESULTADOS E DISCUSSÃO}

As planícies de inundação da Amazônia são consideradas áreas de risco porque seus sistemas vivos ficam mais expostos às adversidades climáticas como os eventos de cheias e vazantes extremas. Segundo Moran (1990), quanto mais baixa a várzea, mais vulneráveis ficam seus habitantes, ou seja, a posição topográfica influencia na intensidade da vulnerabilidade das pessoas que habitam as áreas alagáveis, como é o caso dos moradores de Bracinho e Braço Grande.

Nos últimos anos, os eventos extremos de cheias e vazantes têm se tornado mais frequentes e acontecido de forma mais intensa na Amazônia (ANDRADE et al, 2018), deixando os moradores locais sujeitos às consequências negativas que afetam a moradia, o acesso à água potável, bem como as principais atividades econômicas, como pesca, agricultura, extrativismo, criação de animais e serviços sociais básicos, como saúde e educação.

As consequências desses eventos vão além dos prejuízos físicos. Durante os últimos eventos hidrológicos extremos ocorridos na região, especialmente nos anos de 2012 e 2014, mesmo os moradores do PAE Jenipapo detentores de conhecimentos tradicionais acerca das variações sazonais típicas da várzea, não conseguiram prever a intensidade da cheia e sofreram danos. Assim, já não arriscam mais um palpite em relação ao comportamento do rio e mostram-se receosos quanto ao que possa vir acontecer e ao modo como irão enfrentar as consequências desses extremos em diferentes aspectos do seu cotidiano.

Essas incertezas prejudicam a qualidade de vida dos moradores da área. Segundo Herculano (2000), a dimensão ambiental deve ser um indicador a ser considerado para avaliar a qualidade de vida e o desenvolvimento humano, pois as moradias em áreas de risco afetam negativamente o bem-estar das pessoas.

Uma das mudanças observadas no modo de vida das comunidades estudadas durante as variações de seca e cheia do Lago Jenipapo se refere aos hábitos de alimentação. Dentre os entrevistados, $80 \%$ responderam que modificam sua alimentação conforme as épocas de cheia e seca. No período de enchente e cheia, alimentam-se principalmente de peixe, sendo a pesca também uma fonte de renda nessa época. $\mathrm{Na}$ seca, 
Adaptabilidade ribeirinha diante das variações de seca e cheia do Lago Jenipapo (Manicoré/AM)

os ribeirinhos recorrem a outras fontes de proteína animal, tendo como base principalmente a criação de pequenos animais domésticos, como aves (galinha e pato) e suínos.

Esse resultado também foi observado por Nascimento (2017) em uma comunidade de várzea do Amazonas. A autora afirma que a enchente e a cheia configuram-se como os momentos de pescar, de montar as pontes de madeiras, de suspender os animais, as plantas e as casas.

Apesar da grande importância da pesca na área, os moradores têm percebido uma redução da quantidade de peixe durante as cheias dos últimos anos, e por isso têm recorrido algumas vezes à caça para suprir a necessidade de proteína animal. Geralmente a caça é uma atividade realizada no período de cheia na Amazônia, devido a maior facilidade de acesso às áreas de florestas mais densas por meio dos igarapés e furos (COSTA, 2014). Aqui, há um indicador da importância de analisar a relação entre a redução da quantidade de peixes e o aumento da atividade de caça na área, avaliando-se seu efeito sobre a manutenção da diversidade e da quantidade da fauna silvestre local.

Foi questionado se está ocorrendo alguma ação na área para evitar a escassez do peixe e $80 \%$ dos entrevistados responderam que não, entretanto, há uma percepção da necessidade de ações dessa natureza. Segundo alguns entrevistados: "eu tenho consciência de que se a gente não cuidar, vai sim acabar"; "é preciso diminuir a pesca em alguns lugares do lago e respeitar a época dos peixes". Essas falas demonstram a necessidade de maior atenção do órgão gestor na organização de estratégias que garantam a manutenção desse recurso que é base principal de alimentação e renda para as famílias do PAE Jenipapo.

Outro fator de adaptação observado na área, relacionado às variações de seca e cheia, é o formato da construção das moradias. As casas são do tipo palafita, cujas estruturas correspondem a um tipo de habitação de madeira construída sobre troncos ou pilares também de madeira.

As residências são construídas a uma altura do solo que corresponde ao nível médio de subida das águas do Lago Jenipapo, observado empiricamente pelos moradores. Entretanto, uma peculiaridade observada na área é a construção de casas de dois andares ou "prédios", como denominaram os entrevistados, com o térreo construído diretamente no solo exposto durante a seca.

O andar de cima é o local onde se mora, onde os móveis e objetos importantes para a família são alocados, definido como o lugar "seguro" em relação à cheia. O andar 
Adaptabilidade ribeirinha diante das variações de seca e cheia do Lago Jenipapo (Manicoré/AM)

de baixo é o local de trabalho, visto como secundário, um espaço de insegurança pela possibilidade de inundação. Essa característica indica que o processo de alagação da área onde foram construídas as moradias é recente, pois as moradias alagáveis mais antigas não apresentam essa característica (COSTA, 2014).

Dos entrevistados, $40 \%$ afirmou ter construído o andar superior após a cheia de 2014, que corresponde ao registro da última cheia extrema do Rio Madeira, quando atingiu a marca de 19,74 metros, mais de 3 metros acima da cota de emergência estabelecida para essas áreas (FRANCA \& MENDONÇA, 2015).

Observa-se aqui a importância do desenvolvimento de políticas e programas públicos para a prevenção, respostas e adaptação aos efeitos dos eventos de cheias e secas extremas no Amazonas, uma vez que as medidas governamentais nesses episódios consistem somente nas respostas, com auxílio emergencial às famílias afetadas, quando ocorrem (COSTA et al, 2016).

A sazonalidade de seca e cheia do Lago do Jenipapo também influencia as atividades econômicas das comunidades estudadas. O quadro 1 apresenta as espécies utilizadas para a comercialização, de acordo com as atividades que são fontes de renda às famílias.

Quadro 1: Espécies utilizadas e atividades realizadas na área, de acordo com a sazonalidade do Lago do Jenipapo.

\begin{tabular}{|c|c|c|}
\hline Atividade & Espécies & Período do ano \\
\hline Agricultura & $\begin{array}{c}\text { Mandioca } \\
\text { Banana } \\
\text { Abacate } \\
\text { Melancia }\end{array}$ & Seca \\
\hline \multirow[t]{2}{*}{ Pesca } & $\begin{array}{c}\text { Tucunaré } \\
\text { Acari } \\
\text { Piranha } \\
\text { Tamoatá } \\
\text { Traíra }\end{array}$ & Seca \\
\hline & $\begin{array}{l}\text { Curimatá } \\
\text { Pirapitinga }\end{array}$ & Cheia \\
\hline Extrativismo & $\begin{array}{c}\text { Castanha } \\
\text { Açaí } \\
\text { Borracha }\end{array}$ & Cheia \\
\hline
\end{tabular}

Fonte: Dados coletados em campo.

De acordo com o quadro 1, observa-se que durante a seca os ribeirinhos da área praticam a agricultura e a pesca de algumas espécies de peixe como tucunaré, acari, piranha, tamoatá e traíra e durante a cheia, a atividade de pesca restringe-se a um número 


\section{Adaptabilidade ribeirinha diante das variações de seca e cheia do Lago Jenipapo}

(Manicoré/AM)

menor de espécies, sendo a renda complementada com a atividade extrativista nesse período.

Estudos apontam que há um importante potencial para incremento da agricultura em áreas de várzea no Amazonas, considerando o uso de espécies de ciclo curto (que possam ser colhidas antes da subida das águas) e a boa fertilidade dos solos em relação à disponibilidade de nutrientes às plantas (ALFAIA \& FALCÃO, 1993; FAJARDO et al, 2009). O conhecimento dessas espécies potenciais pode embasar projetos para ampliar a produção agrícola na área.

A maior diversidade de espécies de peixes durante a seca também é destacada por Fabré e Alonso (1998). Os autores afirmam que durante a seca a abundância de recursos pesqueiros aumenta em rios do Estado do Amazonas, porém, esse aumento pode ser atribuído a diminuição da intensidade da atividade pesqueira nesse período, devido a maiores distâncias e a maior dificuldade de acesso dos barcos às áreas de pesca.

O extrativismo durante a cheia também é destacado por Costa (2014) na região do Rio Madeira, devido a maior facilidade de acesso às áreas de florestas mais distantes das margens dos rios por meio de canoas, locais onde geralmente são encontradas áreas nativas de castanhais e seringais.

De modo geral, observa-se que as estratégias adaptativas adotadas pelos ribeirinhos do Lago Jenipapo seguem lógica semelhante àquelas realizadas em outras áreas da Amazônia (FRAXE et al, 2007; PEREIRA, 2007; COSTA, 2014; NASCIMENTO, 2017). Os ribeirinhos adaptam o seu modo de viver nessas áreas em reciprocidade com a natureza, percebendo e respeitando o tempo ecológico dos recursos naturais para organizar sua moradia, alimentação e seu trabalho.

Essa apropriação da natureza é realizada a partir de um entendimento em que todos os elementos do ambiente estão interligados entre si e entre os próprios ribeirinhos (GONÇALVES, 2005). Ao tempo em que os ribeirinhos se adaptam para usar os recursos do lugar, as famílias desenvolvem laços afetivos, que lhes possibilitam a construção de um sentimento de pertencimento, e, portanto, de cuidado com o seu lugar de vida.

\section{CONSIDERAÇÕES FINAIS}

A permanência das comunidades ribeirinhas amazônicas em um meio ecológico de elevada complexidade está condicionada ao domínio dos saberes acumulados sobre o 
Adaptabilidade ribeirinha diante das variações de seca e cheia do Lago Jenipapo (Manicoré/AM)

lugar onde vivem. Exemplo disso é o reconhecimento da redução e até extinção de alguns recursos naturais do Lago Jenipapo pelos moradores locais.

Essa percepção é construída por meio da vivência e da herança cultural, desenvolvendo-se a ideia de que se não houver um consumo equilibrado, não haverá o que consumir. Trata-se de uma lógica orientada por critérios de eficiência reprodutiva, pois o que está em jogo é a reprodução da comunidade e das famílias e não o acúmulo de capital.

Apesar de área estudada ter sido transformada em um assentamento agroextrativista não foi observado efeito significativo nas adaptações construídas pelas famílias. Permanecem os desafios para o enfrentamento das dificuldades relacionadas às variações de seca e cheia do lago.

As estratégias de adaptabilidade observadas no PAE Jenipapo são fundamentais para a permanência dos moradores na área, permitindo-lhes o gerenciamento das dificuldades, dos riscos e a aprendizagem a cada novo evento vivenciado. As habilidades que vão sendo desenvolvidas somente são possíveis a partir de uma vivência integrada com a natureza, proporcionando o conhecimento e criatividade necessárias para sua permanência.

Essas estratégias precisam ser consideradas em planos de governança relacionados à prevenção de eventos climáticos extremos, nesse caso relacionados às secas e cheias severas. As mudanças observadas na área, relacionadas principalmente à percepção da diminuição de recursos necessitam de atenção do poder público, reduzindose as vulnerabilidades das famílias e dando-lhes condições para a melhoria de suas condições de vida.

\section{REFERENCIAS}

ALFAIA, S. S; FALCÃO, N. P. Estudo da dinâmica de nutrientes em solos de várzea da Ilha do Careiro no Estado do Amazonas. Amazoniana, XII (3/4), p 485 - 493, 1993.

ANDRADE, B. S; SINGH, C. L; SANTOS, J. A; GONÇALVES, V. V. C; SIQUEIRASOUZA, F. K; FREITAS, C. E. C. Efeitos das mudanças climáticas sobre as comunidades de peixes na Bacia Amazônica. Revista Ciências da Sociedade (RCS), vol. 2, n. 4, p.107-124, jul/dez 2018.

COSTA, F. C; RAVENA, N; MAGALHÃES, R. Capacidade institucional para governança de risco no interflúvio Purus-Madeira (Amazonas). Revista Brasileira de Ciências Ambientais, No. 39, p. 28 - 46, mar 2016. 

(Manicoré/AM)

COSTA, F. S. A dinâmica dos recursos comuns em Unidades de Conservação e Assentamentos Rurais no Amazonas: uma abordagem fuzzy set. 2014, 365f. Tese (Doutorado em Ciências Socioambientais) - Universidade Federal do Pará, 365f, Belém, 2014.

FABRÉ, N. N; ALONSO, J. C. Recursos ícticos no Alto Amazonas: sua importância para as populações ribeirinhas. Boletim do Museu Paraense Emílio Goeldi, p. 1 - 31, 1998. Disponível em: https://www.researchgate.net/profile/Nidia_Fabre/publication/284662378_Recursos_Ict icos_no_Alto_Amazonas_Sua_Importancia_para_as_populacoes_ribeirinhas/links/568d daef08aef987e5661 cd4/Recursos-Icticos-no-Alto-Amazonas-Sua-Importancia-para-aspopulacoes-ribeirinhas.pdf. Acesso: 09/02/2020.

FAJARDO, J. D. V; SOUZA, L. A. S; ALFAIA, S. S. Características químicas de solos de várzeas sob diferentes sistemas de uso da terra, na calha dos rios baixo Solimões e médio Amazonas. Acta Amazônica, Manaus, vol. 39, no. 4, p. 731 - 740, 2009.

FERRARA, L. D. As cidades ilegíveis: percepção ambiental e cidadania. In: DEL RIO, V; OLIVEIRA, L. (Orgs.). Percepção Ambiental: a experiência brasileira. São Paulo: Studio Nobel, 2a ed, 1999.

FRANCA, R. R.; MENDONÇA, F. A. A cheia histórica do rio Madeira no ano de 2014: riscos e impactos à saúde em Porto Velho (RO). Revista Brasileira de Geografia Médica e da Saúde, v.11, p. 62 - 79, 2015.

FRAXE, T. J. P; PERERIA, H. S; WITKOSKI, A. C. Comunidades ribeirinhas amazônicas: Modos de vida e uso dos recursos naturais. Manaus: EDUA, 223 p, 2007.

GONÇALVES. C. W. P. Amazônia, Amazônias. São Paulo: Contexto, 2a ed, 2005.

HERCULANO, S. C. A qualidade de vida e seus indicadores. In: HERCULANO, S. C (Org). Qualidade de Vida e Riscos Ambientais. Niterói: Eduff, 2000. p. 219 - 246.

MARENGO, J. A.; ESPINOZA, J.C. Extreme seasonal droughts and floods in Amazonia: causes, trends and impacts. International Journal of Climatology, Oxford, 36: 1033$1050,2016$.

MORAN, E. F. A ecologia humana das populações da Amazônia. Michigan: Fondo de Cultura Económica, 367p, 1990.

MORAN, E. F. Adaptabilidade humana: Uma introdução à antropologia Ecológica. Tradução de COIMBRA, C. E; BRANDÃO, M. S. São Paulo: Editora da Universidade de São Paulo, 512 p, 2010.

NASCIMENTO, A. C. Resiliência e adaptabilidade dos sistemas Socioecológicos ribeirinhos frente à eventos climáticos extremos na Amazônia Central. 2017. 139 f. Dissertação (Mestrado em Ciências do Ambiente e Sustentabilidade na Amazônia) Universidade Federal do Amazonas, Manaus, 2017.

OLSON, M. A Lógica da Ação Coletiva. São Paulo: EDUSP, 1999. 
Adaptabilidade ribeirinha diante das variações de seca e cheia do Lago Jenipapo (Manicoré/AM)

PEREIRA, H. S. A dinâmica da paisagem socioambiental das várzeas do Rio SolimõesAmazonas. In: Comunidades ribeirinhas amazônicas: modos de vida e uso dos recursos naturais. FRAXE, T. J. P; PEREIRA, H. S; WITKOSKI, A. C. (Orgs). Manaus: EDUA, p. 07- 52, 2007.

SCHERER, E. F. O defeso e a defesa do meio ambiente. In: II Congresso da Associação Nacional de Pós-Graduação e Pesquisa em Ambiente e Sociedade. Anais eletrônicos... São Paulo: ANPPAS, 2004. Disponível em: http://www.anppas.org.br/encontro_anual/encontro2/GT/GT08/elenise_scherer.pdf. Acesso: 09/05/2019.

STERNBERG, H. O. A Água e o homem na várzea do Careiro. Belém: Catálogo do Museu Paraense Emílio Goeldi, vol. 2, 330 p, 2016.

WORLD HEALTH ASSOCIATION. Division of Mental Health. Qualitative Research for Health Programmes. Geneva: WHA, 1994 